\title{
MEDO DE FALAR EM PÚBLICO: ESTUDO PILOTO DA GLOSSOFOBIA EM CONTEXTO DE ALUNOS UNIVERSITÁRIOS
}

\author{
Miranda $\mathbf{H}$. \\ Alunas do 3ํano de Psicología da Universidade Autónoma de Lisboa (UAL) \\ D'Angiolillo, G. \\ Alunas do $3^{0} a n o$ de Psicología da Universidade Autónoma de Lisboa (UAL) \\ Lava Esteves, M. \\ Docentes Universidade Autónoma de Lisboa (UAL) Portugal \\ Magalhães J. \\ Docentes Universidade Autónoma de Lisboa (UAL) Portugal
}

Recepción Artículo: 15 abril 2020 Admisión Evaluación: 17 abril 2020 Informe Evaluador 1: 17 abril 2020

Informe Evaluador 2: 119 abril 2020

Aprobación Publicación: 20 abril 2020

\section{RESUMO}

0 medo de falar em público - glossofobia - é considerado um fator de grande ansiedade e stress, afetando uma elevada percentagem de pessoas. Sendo considerado um stressor psicossocial, pode levar ao isolamento e, desta forma, impedir o indivíduo de se comunicar. Este estudo exploratório do tipo descritivo, teve como objetivo principal, avaliar o real impacto da glossofobia em alunos, no contexto académico e profissional, a nível psicológico, emocional e físico. Vão ser apresentados os resultados recolhidos de uma amostra de 33 alunos universitários do curso de psicologia do $3^{\underline{a}}$ ano na Universidade Autónoma de Lisboa. Verificados os resultados, verificou-se a existência do medo de falar, mesmo que muitas vezes não verbalizado ou camuflado com uma vergonha ou timidez tomada como traço de personalidade. No âmbito da Psicologia, considerou-se a criação de um plano de intervenção para minimizar o impacto negativo, levando no futuro a aumentar a confiança e a qualidade de vida dos alunos.

Palavras-chave: medo; glossologia; impacto; intervenção; stress

\section{ABSTRACT}

The measure of falar in public: a pilot study of glossophobia in the contexto of university students. Fear of public speaking (glossophobia) is considered a factor of great anxiety and stress and affects a high percentage of people, being considered a psychosocial stressor, which can lead to isolation and thus prevent the individual from communicating.

This work aims to evaluate the real impact of glossophobia on students, in the academic and professional context, at a psychological, emotional and physical level. The results will be presented through an empirical pilot 


\section{MEDO DE FALAR EM PÚBLICO: ESTUDO PILOTO DA GLOSSOFOBIA EM CONTEXTO DE ALUNOS UNIVERSITÁRIOS}

study, carried out on a sample of 33 university students from the 3rd year psychology course at the Autonomous University of Lisbon. Once the results were verified, an intervention plan was considered to minimize the negative impact, leading to an increase of the confidence and quality of life of the students.

Keywords: fear of public speaking; glossology; impact in the life of people; future intervention

\section{INTRODUÇÃO}

Falar, é uma palavra curiosa. Quando se reflete à cerca da sua origem, do seu significado, falar, pretende expressar, seja, um pensamento, um sentimento ou partilhar conhecimento; desprovido de medos, de bloqueios. Quando colocada esta ação de falar em público, algo que é feitos todos os dias, independentemente da profissão, do seio familiar, dos amigos, trabalho ou escola. Quando se fala tem-se como objetivo, comunicar, partilhar, estabelecer relações, colocar algo em comum. Esta ação, implica um conjunto de símbolos linguísticos, um processo que gera uma comunicação, utilizada desde sempre, faz parte da evolução humana (Mattelart, A., Mattelart, M., Taponier, S. G., \& Cohen, J. A., 1998).

A fala, poderia ser considerada como uma "dança" simples, entre pessoas numa interação social, da revisão de literatura, encontra-se na experiência dos autores enquanto seres sociais, bem como de um estudo piloto empírico, uma realidade bem mais complexa; vividas por uma grande percentagem das pessoas contactadas, onde a "dança" se vai complexificando.

As qualidades comunicativas são apreendidas ao longo do tempo, através

das relações, sociais e culturais. É um processo natural do desenvolvimento, ao que se junta um conjunto de regras. Uma técnica que se pode melhorar e desenvolver esta capacidade humana. Falar para públicos é uma necessidade diretamente ligada à carreira escolhida, um fator muito significativo em estudos universitários.

Na elaboração, preparação e treino do discurso, os resultados são satisfatórios, no entanto quando chega 0 momento de 0 fazer junto do público, as coisas nem sempre corre como planeado, sendo por isso considerado um stressor psicossocial (Marinho, Medeiros, \& Teixeira, 2019).

\section{DESENVOLVIMENTO}

Glossofobia, a palavra grega tem em si, um significado de associação, ao medo ou pavor de falar em público, quando a dividimos na sua origem Glosso = língua, efobos = medo ou pavor (Hancock, A., Stone, D., Brundage, S., \& Zeigler, M., 2010).

Este medo tem por detrás uma ansiedade, um nervosismo, que ocorre vários dias ou mesmo semanas antes de fazer uma apresentação, afeta uma grande percentagem da população.

Apesar de ser um medo consciente, não é fácil de controlar, afetando a autoestima e outras áreas da vida da pessoa. Este estudo verifica-se uma maior percentagem em mulheres (Khan, Ismail \& Ali, 2015).

"A sessão de medo, de incapacidade, inibiu muitas vezes a minha expressão, a minha comunicação, em reuniões de trabalho, o rosto corava, quase que desejava que o mundo acaba-se naquele momento, não conseguia expressar o que pensava, cheguei mesmo a ficar com febre, uma defesa interna, para não 0 fazer. Foram muitas a situações em que este medo me acompanhou ao longo da adolescência e da vida adulta" (sic).

Darwin (2016) já se referia ao medo como um estado emocional irracional, parece derivar do que é reprimido e perigoso, podendo mesmo ser intensificado surgindo o terror. 0 medo conduz claramente a uma alteração física captada pelos sentidos, podendo ser observado na expressão, como arregalar de olhos, respiração suspensa, aceleração do ritmo cardíaco e a respiração torna-se mais rápida, criando situações de imobilidade ou fuga. Outros alterações inexplicáveis com transpirar" suores frios" a boca seca, voz torna-se hesitante, sintomas que foram muitos uteis ao longo do tempo como forma de sobrevivência do ser humano.

Como se pode constatar neste depoimento obtido durante esta investigação: "Estar no centro das atenções não é fácil, especialmente para aqueles que estão inseguros sobre si mesmos, surge uma timidez, uma insegurança pessoal. É o que acontece comigo. Tenho a certeza de que a minha timidez vem da minha insegurança, da falta de autoestima, o que muitas vezes me levou a ficar ansiosa quando falava para uma audiência. Embora eu 
não pense em mim como uma pessoa tímida quando estou em família, no momento em que falo para uma planteia, ter os olhares todos em mim, fico muito envergonhada. 0 excesso de peso que tinha em criança foi talvez um dos fatores que tive que enfrentar, estava sempre a comparar-me com os outros, tinha sempre presente 0 julgamento. Por outro lado, fui sempre evitando situações de exposições publica. A entrada para a universidade, levou-me a lidar com outros medos, inseguranças, aprendi a transformá-Ios em forças, continuei a ficar com 0 rosto rosado, mas conseguia controlar. Quando me candidatei ao programa Erasmus, enfrentei novas situações, estar isolada num país com outra língua, trouxe-me mais confiança. Hoje com 25 anos, continuo a ser tímida, mas sei lidar com o medo (sic).

\section{Processos cognitivos e crenças}

0 medo de falar em publico está também relacionado com processos cognitivos, visto como uma pressão social, onde a presença de audiência amplia as memórias emocionais. Os padrões de pensamentos surgem de crenças, que se organizam através das experiências, normalmente têm uma forte carga emocional, vão-se enraizando desde crianças, instalam-se como ideias fixas, como verdades. As crenças interiorizadas têm relação direta com aspetos negativos sobre os medos, uma dinâmica psicológica de pensamentos, de incapacidade, medo de errar e humilhação, uma necessidade de ser aceite socialmente. A combinação das crenças emocionais com a tensão de falar em público, leva a uma reduz das capacidades de comunicar (Gellatly, Beck, 2016).

Nas questões cognitivas, o medo de falar em público está relacionado com o sistema límbico, ligado a questões emocionais de memórias que fizeram parte da aprendizagem, condicionando ou possibilitando comportamentos de respostas intuitivas. Na leitura referida entende-se o septo como uma estrutura do sistema límbico onde se verifica uma associação do medo e da raiva, um processo inconsciente ligado à sobrevivência, quando consciente pode servir como motivação para enfrentar este medo (Sternberg e Sternberg, 2012).

Os fatores como novidade (conteúdo), o desconhecido (não conhecer o público), o número da audiência, são também fatores muito relevantes no entendimento desta fobia. Sendo de considerar a variável cultural (Ajeng, Ariffudin \& Mulawarman, 2017).

Os sintomas de ansiedade e stress, são os mais referidos, podendo desencadear ataques de pânico, este medo tem muito impacto na vida da pessoa, sendo afetadas várias áreas de vida, familiar, escolar, trabalho, levando muitas vezes ao isolamento, impedindo em algumas situações a evolução na carreira, condicionamento nas atividades sociais, baixa produtividade, mexendo diretamente com a autoestima (D’El Rey, Pacini, 2005).

Na partilha de dois testemunhos (nas suas experiência enquanto estudantes) observaram de perto 0 impacto deste medo nas apresentações de trabalhos na faculdade, sendo evidente a perturbação dos colegas a nível emocional e psicológico, impedindo de mostrar as suas verdadeiras competências. Depreendemos dessa forma a necessidade de

Intervenção Psicológica, para um maior entendimento das questões que estão por de trás destas distorções emocionais, podendo assim levar a uma tomada de consciência, permitindo desenvolver competências para superar esse medo, e dessa forma promover a mudança. As questões mais práticas tais como: a) preparação; b) conhecimento do conteúdo; c) treino; d) conhecer a audiência, são algumas das técnicas que podem ajudar a minimizar o impacto (Beck, 2013; Silva, 2014)

\section{METODOLOGIA DA INVESTIGAÇÃO}

\section{Objetivos do estudo piloto}

Este estudo piloto empírico, teve com objetivo, conhecer o real impacto do medo de falar em publico em alunos universitários do curso de psicologia do $3^{a}$ ano na UAL, em respostas as questões: (a) Qual o real impacto do medo de falar em público? (b) Quais os recursos que podemos utilizar para minimizar esse impacto? (c) Que processos internos (físicos e psíquicos) estão envolvidos?

Estas questões conduziram à necessidade, criar planos de intervenção futuro, para aumentar a satisfação e qualidade de vida dos alunos. 


\section{MEDO DE FALAR EM PÚBLICO: ESTUDO PILOTO DA GLOSSOFOBIA EM CONTEXTO}

DE ALUNOS UNIVERSITÁRIOS

\section{Método}

0 estudo foi realizado através de um questionário online com questões que permitem identificar os sintomas psicológicos, físicos e emocionais, impacto na vida das pessoas, assim como dados demográficos, em estudantes universitários de ambos os géneros, com idades compreendias entre os 20 e os 63 anos. 0 questionário continha 16 perguntas.

\section{Apresentação e discussão dos resultados}

Neste estudo, verificou-se que os impactos considerados mais relevantes para o objetivo proposto foram ao nível psicológico, físico, emocional e limitações.

Tabela 1. Dados Demográficos - Idade

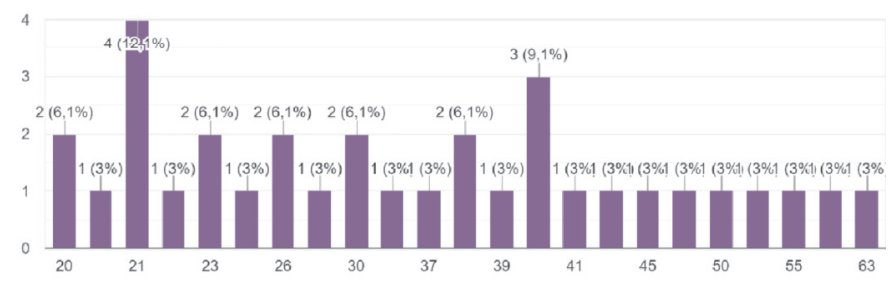

Foram recolhidas 33 respostas, com idade compreendidas entre ao 20 e 63 anos.

Tabela 2. Dados Demográficos - Género

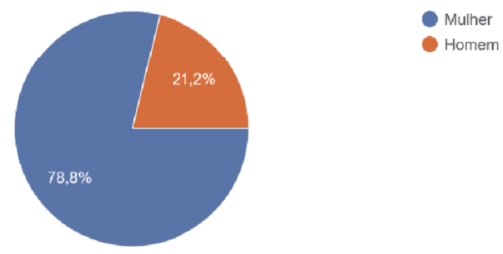

Verificou-se uma percentagem de (78.8\%) mulheres, (21. 2\%) homens.

Tabela 3. Sente medo de falar em público?

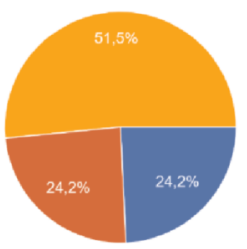

Sim

Em algumas situaçôes

Das respostas obtidas $24.2 \%$ das pessoas respondeu sim, sendo que (51.5\%) respondeu em algumas situações, $(24.2 \%)$ respondeu que não. 


\section{Tabela 4. Quando percebeu que tinha medo de falar em público?}

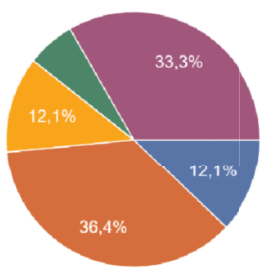

Infância

Adolescência

Vida Adulta

Actualmente

Não Aplicável

Nesta questão com $(36,4 \%)$ responderam que foi na adolescência, na infância e vida adulta responderam a mesma percentagem (21.1\%).

\section{Tabela 5. Que reações físicas sente ao falar em público?}

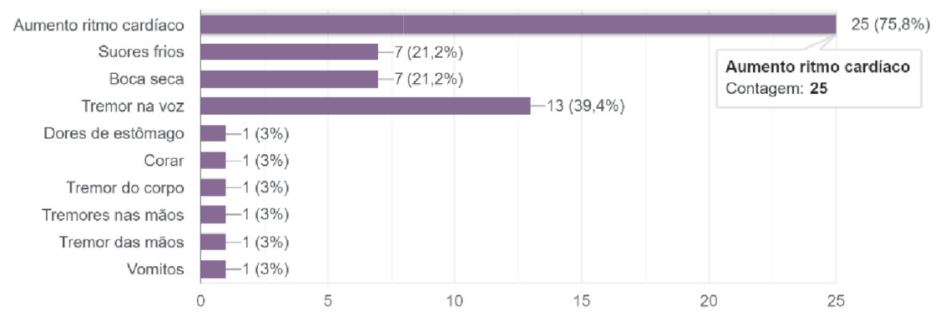

Nas reações físicas, foram identificados sintomas somáticos como 0 aumento do ritmo cardíaco referido com (75.8\%), seguido com (39.4\%) o tremor na voz, com (21.2\%) suores frios e a boca seca.

Tabela 6. Que reações psicológicas sente ao falar em público?

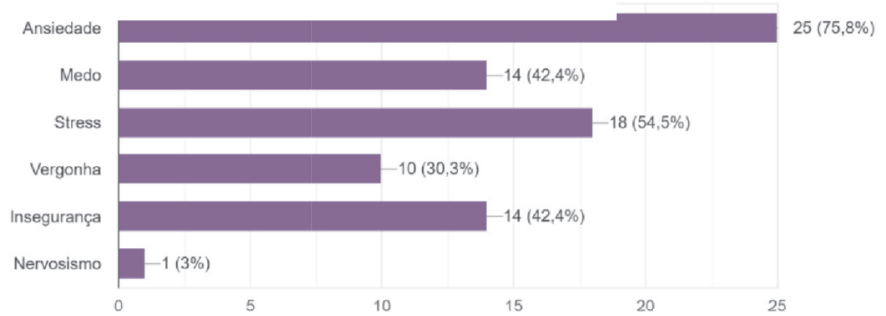

$\mathrm{Na}$ questão das reações psicológicas e emocionais, foi visível que o sintoma de ansiedade causa mais impacto referida com (75.8\%), seguido do stress com (54.5\%), o medo e insegurança com (42.4\%) vergonha com $(30.3 \%)$. 


\section{MEDO DE FALAR EM PÚB BLICO: ESTUDO PILOTO DA GLOSSOFOBIA EM CONTEXTO}

DE ALUNOS UNIVERSITÁRIOS

Tabela 7. Quais as principais limitações ao falar em público? (Identifique 4)

Não conseguir expor a opinião; a falta de confiança; falta de autoestima; o ser observado; foram os mais referidos.

Tabela 8. Em que dimensões da sua vida sente medo ao falar em público?

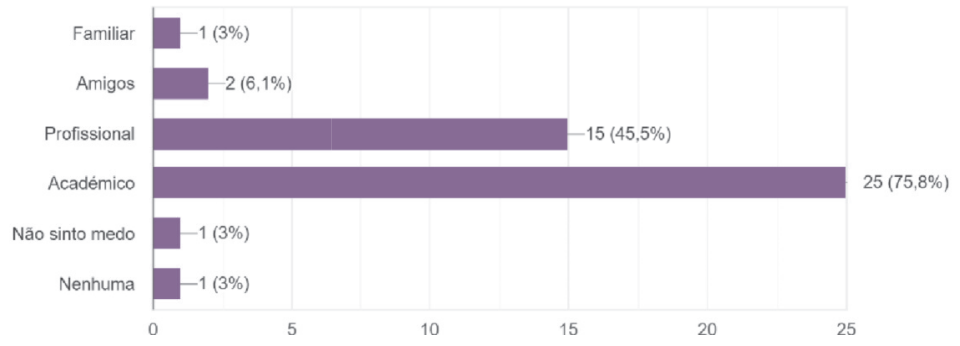

0 meio académico, com (75.8\%), foi o mais referido, seguido do profissional com (45.5\%) das respostas, nos amigos com (6,1\%) com menos relevância o meio familiar com (3\%).

Tabela 9. Procura evitar falar em público?
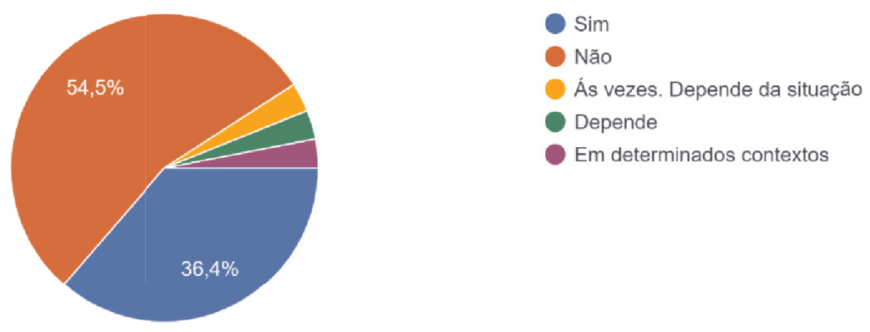

$(54,5 \%)$ respondeu que não, a resposta sim teve (36.4\%) das respostas.

Tabela 10. Consegue imaginar-se a falar em público sem qualquer condicionamento?
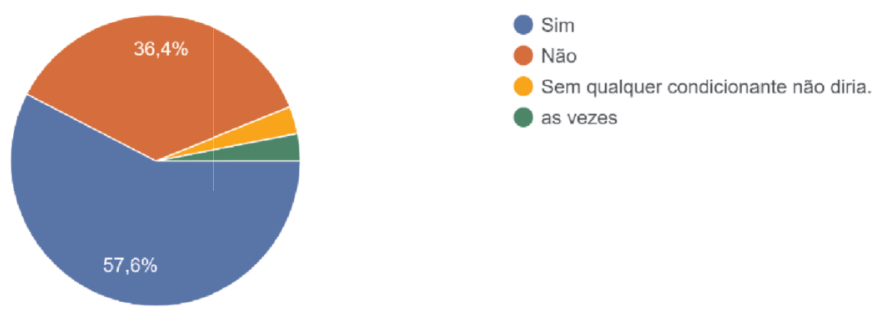

Quando projetados para o futuro $(57,6,4 \%)$ dos estudantes respondem que sim, mostrando uma vontade de superar o medo, já $(36,4 \%)$ respondeu que não. 
Tabela 11. Aceitaria participar em formações/workshops para gerir o medo de falar em público?

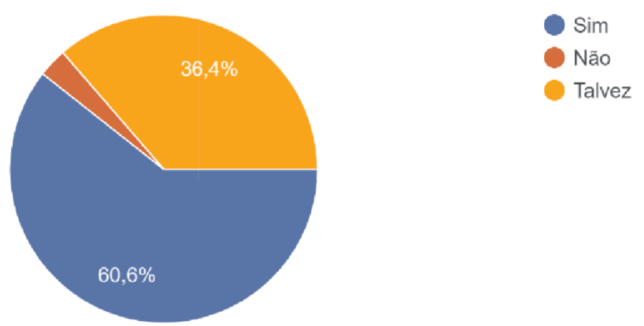

Quando questionados na possibilidade de participar em formações/workshops $(60,6 \%)$ responderam que sim, $(36,6 \%)$ talvez. Validando assim a importância da intervenção para a superação deste medo.

Sendo um estudo piloto, pretendeu-se indagar e procurar fazer uma primeira análise mais orientada no impacto do medo de falar em publico, e nas motivações para o superarem, com o objetivo de se criar uma metodologia a partir dos resultados; que permita intervir nas necessidades indicadas pelo estudo. Procurando minimizar o impacto do medo de falar em público, permitir desenvolver recursos internos e externos, como os seus efeitos a nível físico, e psíquicos.

Possa este estudo inicial ser o trampolim para se desenvolver novos estudos empíricos, para apurar outras necessidades, com uma amostra de maiores dimensões e posteriormente a respetiva divulgação dos resultados na comunidade académica para que juntos se possa pensar mais e melhor!

\section{CONCLUSÃO}

Fazer este trabalho foi também uma viagem a várias memórias, várias experiências dos participantes (sic); 0 medo de falar um publico é efetivamente um bloqueio que impede as pessoas de viverem, de serem livres. A psicologia tem um papel fundamental neste caminho de ajuda, na intervenção e prevenção destes condicionamentos, nestes "muros" de sistemas que não nos ensinam a comunicar, a expressar, a pensar, apenas a seguir, cumprir um conjunto de pressupostos.

Ser um psicólogo é estar disponível, flexível para proporcionar a que cada pessoa seja responsável pelas suas escolhas; escolhas conscientes, escolhas com opções, de preferência que não tenham condicionamento. Ser um psicólogo é sem querer ter a chave de toda as soluções é promover a inteligência emocional, querer contribuir para que cada pessoa conheça o seu mundo interno, para se poder relacionar no seu meio social. Para que se comunique cada vez mais e melhor de uma forma assertiva, como pessoas realizadas e felizes!

\section{REFERÊNCIAS BIBLIOGRÁFICAS}

Beck, J., (2013). Terapia Cognitiva-Comportamental: teoria e prática. 2ª Ed. Porto Alegre. Artmed. 413 p.

Darwin, C. (2016). A Expressão das Emoções no Homem e nos Animais. Relógio D’água.

Gellatly, R., \& Beck, A. T. (2016). Catastrophic thinking: A transdiagnostic process across psychiatric disorders. Cognitive Therapy and Research, 40(4), 441-452.

D'El Rey, G. J. F., \& Pacini, C. A. (2005). Medo de falar em público em uma amostra da população: Prevalência, impacto no funcionamento pessoal e tratamento. Psicologia: Teoria e Pesquisa, 21(2), 237-242. Disponível em: https://doi.org/10.1590/S0102-37722005000200014

Gellatly, R., \& Beck, A. (2016). Catastrophic Thinking: A Transdiagnostic Process Across Psychiatric Disorders. Cognitive Therapy \& Research, 40(4), 441-452. Disponivel em: https://bon.ual.pt:2238/10.1007/s10608-016-9763-3

Hancock, A., Stone, D., Brundage, S., \& Zeigler, M., (2010). Public speaking attitudes: Does curriculum make a difference? Journal of Voice, 24(3), 302-307. Disponível em: https://bon.ual.pt:2238/10.1016/j.jvoice.2008.09.007 


\section{MEDO DE FALAR EM PÚBLICO: ESTUDO PILOTO DA GLOSSOFOBIA EM CONTEXTO}

DE ALUNOS UNIVERSITÁRIOS

Khan, F., Ismail, S., Shafique, M., Ghous, K., \& Ali, A. (2015). Glossophobia among Undergraduate Students of Government Medical Colleges in Karachi. 2.

Marinho, A. C. F., Medeiros, A. M. D., Lima, E. D. P., Pantuza, J. J., \& Teixeira, L. C. (2019). Prevalência e fatores associados ao medo de falar público. In CoDAS (Vol. 31, No. 6). Sociedade Brasileira de Fonoaudiologia.

Mattelart, A., Mattelart, M., Taponier, S. G., \& Cohen, J. A. (1998). Theories of communication: A short introduction. Thousand Oaks, CA: Sage Publications Ltd. Disponível em: http://bon.ual.pt:2061/login.aspx?direct=true\&db=psyh\&AN=1999-02059-000\&lang=pt-pt\&site=ehost-live

Silva, M., (2014). Terapia Cognitiva-Comportamental: Da teoria a prática. Psico-USF, 19(1), 167-168. https://doi.org/10.1590/S1413-82712014000100016

Sternberg, R. J., Sternberg, K., \& Mio, J. S. (2012). Cognitive psychology (6th ed). Belmont, CA: Wadsworth/Cengage Learning.

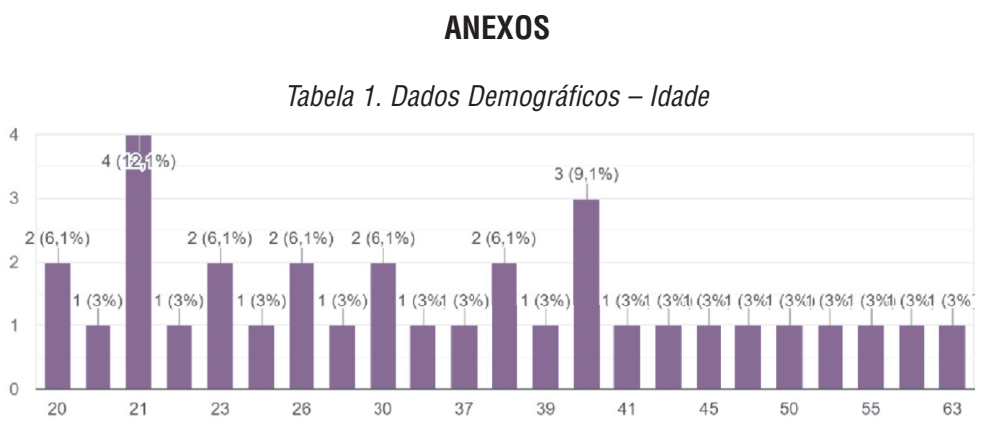

Tabela 2. Dados Demográficos - Género

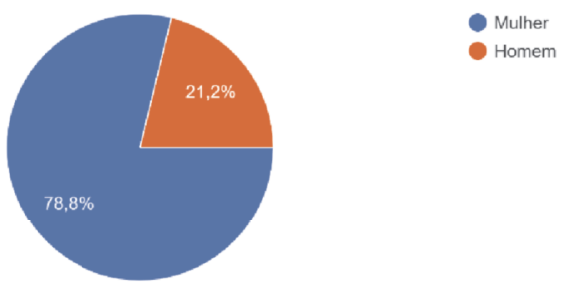

Tabela 3. Dados Demográficos - Género

Naturalidade

33 respostas

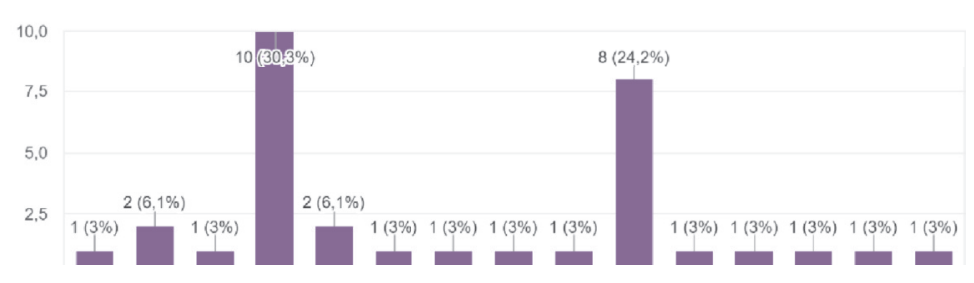


Tabela 4. Sente medo de falar em público?

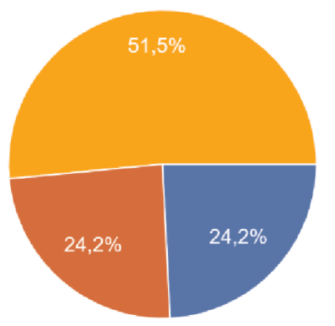

Sim

Não

Em algumas situações

Tabela 5. Quando percebeu que tinha medo de falar em público?

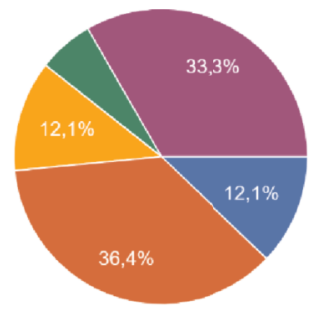

Infância

Adolescência

Vida Adulta

- Actualmente

Não Aplicável

Tabela 6. Que reações físicas sente ao falar em público?

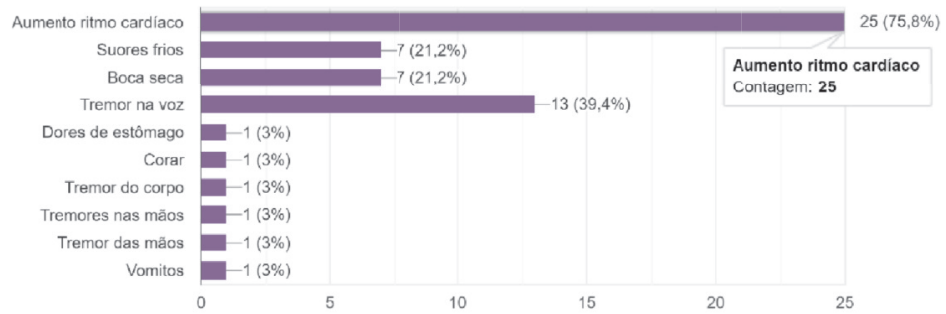

Tabela 7. Que reações psicológicas sente ao falar em público?

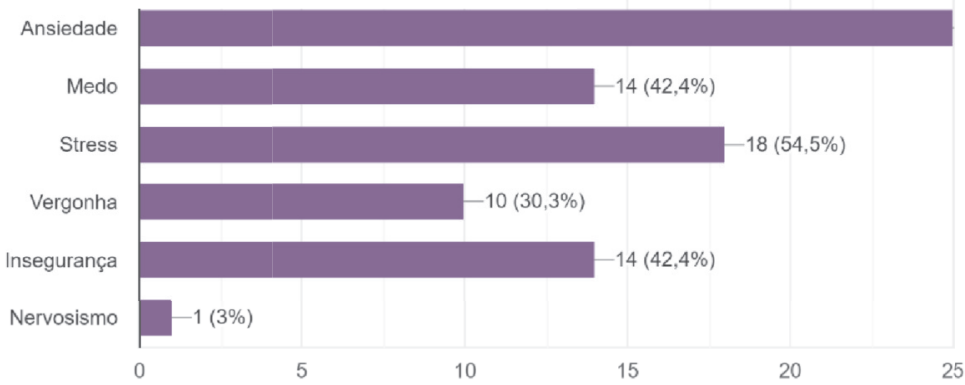


Tabela 8. Em que dimensões da sua vida sente medo ao falar em público?

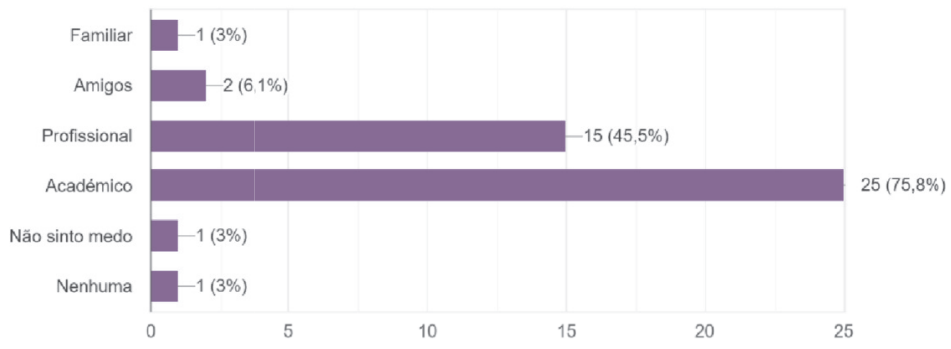

Tabela 9. Procura evitar falar em público?

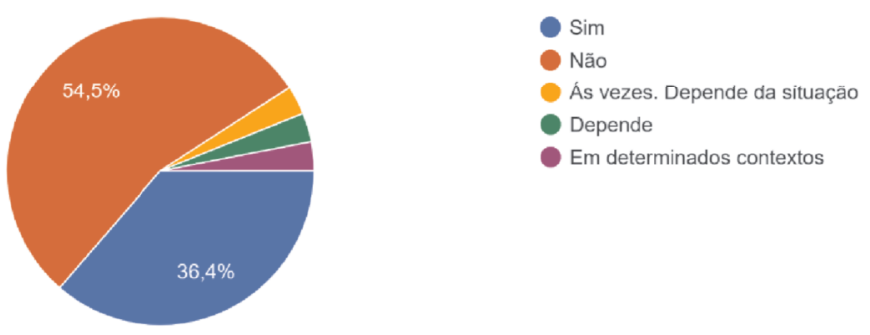

Tabela 10. Consegue imaginar-se a falar em público sem qualquer condicionamento?

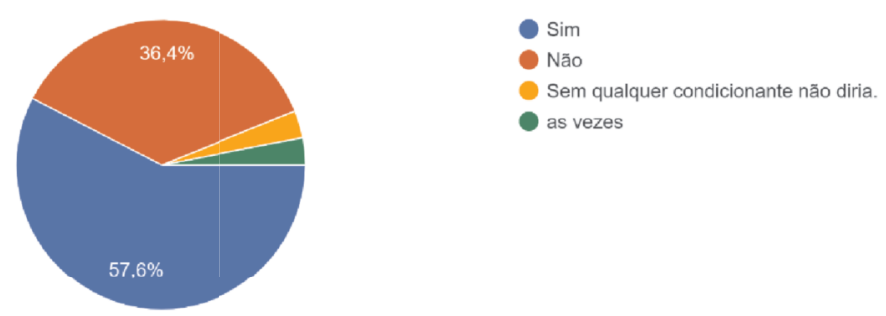

Tabela 11. Aceitaria participar em formações/workshops para geri o medo de falar em público?

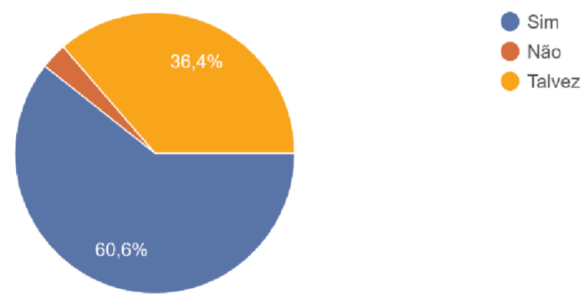

